\title{
Specificity and Sufficiency of EphB1 in Driving the Ipsilateral Retinal Projection
}

\author{
Timothy J. Petros, ${ }^{1}$ Brikha R. Shrestha, ${ }^{1}$ and Carol Mason ${ }^{1,2,3}$ \\ Departments of ${ }^{1}$ Neuroscience, ${ }^{2}$ Pathology and Cell Biology, and ${ }^{3}$ Ophthalmology, Columbia University, College of Physicians and Surgeons, New York, \\ New York 10032
}

At the optic chiasm, retinal ganglion cell (RGC) axons make the decision to either avoid or traverse the midline, a maneuver that establishes the binocular pathways. In mice, the ipsilateral retinal projection arises from RGCs in the peripheral ventrotemporal (VT) crescent of the retina. These RGCs express the guidance receptor EphB1, which interacts with ephrin-B2 on radial glia cells at the optic chiasm to repulse VT axons away from the midline and into the ipsilateral optic tract. However, because VT RGCs express more than one EphB receptor, the sufficiency and specificity of the EphB1 receptor in directing the ipsilateral projection is unclear. In this study, we use in utero retinal electroporation to demonstrate that ectopic EphB1 expression can redirect RGCs with a normally crossed projection to an ipsilateral trajectory. Moreover, EphB1 is specifically required for rerouting RGC projections ipsilaterally, because introduction of the highly similar EphB2 receptor is much less efficient in redirecting RGC fibers, even when expressed at higher surface levels. Introduction of EphB1-EphB2 chimeric receptors into RGCs reveals that both extracellular and juxtamembrane domains of EphB1 are required to efficiently convert RGC projections ipsilaterally. Together, these data describe for the first time functional differences between two highly similar Eph receptors at a decision point in vivo, with EphB1 displaying unique properties that efficiently drives the uncrossed retinal projection.

\section{Introduction}

Retinal fibers converge at the ventral diencephalon to form the optic chiasm, the first step in patterning binocular vision. In mice, the ipsilateral retinal ganglion cell (RGC) projection arises from the peripheral ventrotemporal (VT) crescent of the retina and approaches then turns away from the optic chiasm midline. Optic chiasm cells express a contact-dependent cue that inhibits outgrowth specifically from VT RGCs (Marcus et al., 1995; Wang et al., 1995). Insights into the identity of this cue came from studies on Xenopus (Nakagawa et al., 2000) and were extended to mice, where EphB1 is upregulated in the peripheral VT crescent and ephrin-B2 is upregulated at the optic chiasm midline (Williams et al., 2003). This repulsive receptor-ligand interaction directs the ipsilateral retinal projection.

Eph receptors are divided into two subfamilies (EphAs and EphBs) that primarily interact with their corresponding family of ligands (ephrin-As and ephrin-Bs), with extensive receptor-ligand promiscuity within each subfamily (Flanagan and Vanderhaeghen, 1998). Multiple Eph receptors (and ephrins) are com-

\footnotetext{
Received Nov. 24, 2008; revised Feb. 3, 2009; accepted Feb. 9, 2009.

This work was supported by National Institutes of Health Grants F31 NS051008 (T.J.P.) and R01 EY12736 (C.M.). We thank J. W. Tsai and R. Vallee for help with the electroporation experiments; S. Williams and A. Beg for advice on the molecular cloning; P. Scheiffele, T. Jessell, J. Dodd, E. Herrera, F. Doetsch, H. Wichterle, P. Faust, and S. Brown for sharing reagents and equipment; and R. Blazeski and M. Melikyan for expert technical assistance. We are grateful to T. Sakurai, A. Kania, P. Scheiffele, and members of the Mason laboratory for helpful discussion and comments on this manuscript.

Correspondence should be addressed to Carol Mason, Department of Pathology and Cell Biology, Columbia University, College of Physicians and Surgeons, 14-509 P\&S Building, 630 West 168th Street, New York, NY 10032. E-mail:cam4@columbia.edu.

DOI:10.1523/JNEUROSCI.5655-08.2009

Copyright $\odot 2009$ Society for Neuroscience $\quad$ 0270-6474/09/293463-12\$15.00/0
}

monly colocalized in the same cells throughout development, notably in the retina and superior colliculus/tectum (McLaughlin and O'Leary, 2005), thalamus (Dufour et al., 2003), cerebral cortex (Yun et al., 2003), and the developing limb (Eberhart et al., 2000; Kania and Jessell, 2003; Luria et al., 2008), leading to overlapping and compensatory functions. For example, in the retinocollicular/retinotectal projection, the relative levels of EphA receptors, and not the specific subtype of EphA receptor, govern proper topographic targeting (Brown et al., 2000; Lemke and Reber, 2005). Conversely, hippocampal neurons and cortical pyramidal cells express EphB1-B3, but only EphB1 and EphB2 contribute to spine morphogenesis in the hippocampus and primarily EphB2 in cortical neurons (Henkemeyer et al., 2003; Kayser et al., 2006). Thus, the functional redundancy and specificity of Eph receptors in vivo appears to be context dependent.

In the murine retina, EphB2 is expressed in a high ventral-tolow dorsal gradient, and EphB3 is expressed throughout the RGC layer (Williams et al., 2003; McLaughlin and O'Leary, 2005). Therefore, VT RGCs express EphB1-B3. Examination of knockout mice revealed that EphB1 appears to be the only receptor required for driving the ipsilateral projection, with EphB2 playing a minor role (Williams et al., 2003). Thus, in contrast to the retinocollicular/retinotectal projections, the specific subtype of $\mathrm{EphB}$ receptor (EphB1), and not the net level of EphB receptors, may direct the ipsilateral retinal projection. The issue of Eph receptor specificity versus net Eph receptor levels has not been directly examined in the optic chiasm.

In this study, we examined the sufficiency and specificity of EphB1 in directing the ipsilateral RGC projection. We used in utero retinal electroporation to demonstrate that ectopic EphB1 
expression converts crossed RGC projections to an ipsilateral fate. In addition, we compare and contrast similar EphB receptors to elucidate the domains of the EphB1 receptor required for guiding the ipsilateral retinal projection. These experiments reveal that EphB2 is less efficient than EphB1 in redirecting non-VT RGC axons ipsilaterally. Introduction of EphB1-EphB2 chimeric receptors into RGCs indicated that the increased efficiency requires both the extracellular and juxtamembrane (JM) domains of EphB1. These results demonstrate functional differences between similar EphB receptors in vivo at a well characterized decision point.

\section{Materials and Methods}

Animals. C57BL/6J mice were kept in a timed-pregnancy breeding colony at Columbia University. Embryonic day 0 (E0) was defined as midnight on the day a plug was found. Animals were treated according to the National Institutes of Health Guidelines for Care and Use of Laboratory Animals, and the Columbia University Institutional Animal Care and Use Committee approved our mouse protocols.

Preparation of expression constructs. Full-length murine EphB1 was obtained via expressed-sequence tag clone 6400265 from the IMAGE Consortium. Murine EphB2 was obtained in the pMT21 vector (Williams et al., 2003). The hemagglutinin (HA) tag was added to the $5^{\prime}$ end by cloning full-length EphB1 and EphB2 into pcDNA3.1/Hygro(+) plasmid (Invitrogen), which contained a "signal sequence-HA" insertion (gift from P. Scheiffele, Columbia University, New York, NY). The HAtag is present in all EphB constructs used in this study. The green fluorescent protein (GFP) construct was a gift from A. Beg (Columbia University), and the Zic2 construct was a gift from E. Herrera (Instituto de Neurociencias de Alicante, Alicante, Spain).

For EphB1 point mutations, the Stratagene Quikchange XL SiteDirected Mutagenesis kit was used with the following primers and their reverse complements (mutated sequences are underlined): (1) kinase dead EphB1 receptor (KD EphB1) mutant (K651Q), 5'-GGAAATCTATGTGGCCATCCAGACCCTGAAGGCTGG-3'; (2) 2Y-E EphB1 mutant (Y594E/Y600E), 5'-GGATGAAGATCGAGATTGACCCATTCACTGAGGAGGACCCCAATGAAGC-3'; (3) EphB1 Y928F, 5' -CCATCAAAATGGTCCAGTTCAGGGACAGCTTCC-3'; and (4) EphB1DSAM, 5'-CCCAGACTTCACGGCCTGAACCACCGTGGATGAC-3'.

For the intracellular swaps (EphB1out-B2in and EphB2out-B1in), a NotI site was inserted just outside the putative transmembrane region by performing overhang PCRs with the following primers (NotI site underlined): 1) EphBlout, 5'-TGCTGTCTCATCATTTTGGC-3' and 5'AAAGCGGCCGCTCTTGTAATCATC-3'; 2) EphB2out, 5' -TGCTGTCTCATCATTTTGGC- $3^{\prime}$ and $5^{\prime}$-AAAGCGGCCGCTCTGGTACTCGGC-3'; 3) EphBlin, 5' -AGCCCAGTTTCTATGTGGTCTCC-3' and 5' AAAAGCGGCCGCAGAGAGCAGATA-3'; and 4) EphB2in: 5' -AGCCCAGTTTCTATGTGGTCTCC- $3^{\prime}$ and $5^{\prime}$ - CCAAGCGGCCGCAAGGAAAAGCTA-3'. The "out" PCRs were digested with NotI and XmaI, and the "in" PCRs were digested with NotI and XhoI. The desired products were then ligated into the proper backbone to produce EphB1out-B2in and EphB2out-B1in constructs.

For the sterile alpha motif (SAM) domain swap mutations (EphB1B2T300 and EphB2-B1T300), EphB1 and EphB2 constructs were digested with $B c l$ and $X h o I$, then these products were ligated into the other backbone to produce EphB1-B2T300 and EphB2-B1T300 constructs.

For the terminal 6 (T6) residue swaps (EphB1-B2T6 and EphB2B1T6), overhang PCRs were performed with the following primers (T6 residues underlined): 1) EphB1-B2T6, 5'-TCAAACCTCTACAGACTGGATCTGGTTCATCTGGACCCTCAT- $3^{\prime}$ and $5^{\prime}$-AGCCGGAGCAACCCAATGGC-3'; and 2) EphB2-B1T6, 5' -TCACGCCATTACCGATGGTGACTGGTTCATCTGGGCCCGCAT- $3^{\prime}$ and $5^{\prime}$-ATCGGCCGTGTCCATCATGC- $3^{\prime}$. These blunt-end PCR products were inserted into pCR-Blunt using the Zero Blunt PCR cloning kit (Invitrogen), digested with $B c l \mathrm{I}$ and $\mathrm{XhoI}$, and the desired regions were then ligated into the other backbone, similar to the SAM domain swaps. All cloning was performed in either MAX Efficiency DH5 $\alpha$ Competent Cells (Invitro- gen), XL10-Gold Ultracompetent Cells (Stratagene), or $\mathrm{dam}^{-} / \mathrm{dcm}^{-}$ Competent Escherichia coli (New England Biolabs).

In utero retinal electroporation and analysis. A procedure similar to the one used in this study was described previously (Garcia-Frigola et al., 2007). E13.5- and E14.5-stage timed pregnant female mice were anesthetized with an intraperitoneal injection of $0.12 \mathrm{ml}$ of a 1:0.2:4.6 volume mix of ketamine $(100 \mathrm{mg} / \mathrm{ml})$ :xylazine $(100 \mathrm{mg} / \mathrm{ml})$ :saline. A vertical incision was made on the midline of the abdomen to expose the uterine horns. DNA solution $(0.5 \mu \mathrm{g} / \mathrm{ml}$ GFP in the absence or presence of 5.0 $\mu \mathrm{g} / \mathrm{ml} \mathrm{HA}$-EphB DNA or Zic2 plus $0.03 \%$ Fast Green Dye in distilled water) was loaded into a graduated pulled-glass micropipette, and 0.1$0.5 \mu \mathrm{l}$ was carefully injected into one retina of an embryo, ideally filling the space between the retinal pigment epithelium (RPE) and the outer retinal layer. The electroporation technique does not work well when DNA is injected into the vitreous, in agreement with previous observations (Matsuda and Cepko, 2004; Garcia-Frigola et al., 2007). Tweezertype electrodes (CUY650-P7; Nepa Gene) were then placed around the head (with the "+" electrode near the injected retina), and five $50 \mathrm{~ms}$ square current pulses were delivered ( $45 \mathrm{~V}$ for E14.5, 35V for E13.5) at $950 \mathrm{~ms}$ intervals using an electroporator (ECM 830; Harvard Apparatus). After repeating this procedure for the desired number of embryos, the peritoneum was sutured, the skin was stapled closed, and the embryos were allowed to develop normally.

At E18.5, pregnant mothers were killed, and embryos were perfused with $4 \%$ paraformaldehyde (PFA). Retina were removed and examined with a fluorescent dissecting microscope for $\mathrm{GFP}^{+}$fluorescence. All $\mathrm{GFP}^{+}$retina were immunostained for GFP, HA (or Zic2), and neurofilament. Heads were then immersed in $30 \%$ sucrose in PBS, cryosectioned (20 $\mu \mathrm{m}$ sections), and immunostained for GFP, HA, and neurofilament. Analysis was only performed on embryos in which the most peripheral $300 \mu \mathrm{m}$ of the VT crescent did not contain $\mathrm{GFP}^{+}$cells, because this is the region that contains ipsilaterally projecting RGCs identified by retrograde backfills (Williams et al., 2006) (data not shown). For each sectioned head, three evenly spaced sections of the contralateral and ipsilateral optic tract (OT) were taken, and the GFP signal within each OT section was recorded (supplemental Fig. 1, available at www.jneurosci. org as supplemental material). A ratio of " $\mathrm{GFP}^{+}$signal in ipsilateral $\mathrm{OT} / \mathrm{GFP}^{+}$signal in ipsilateral plus contralateral OT" was determined for each of the three levels of section, which were then averaged to produce a "percentage of $\mathrm{GFP}^{+}$signal in ipsilateral OT" for each embryo. Analysis was performed blind to which DNA construct was electroporated.

In some instances, the heads were not sectioned, and instead semiintact visual system preparations were immunostained for GFP to visualize axons in the optic nerve, optic chiasm, and OTs. In these samples, two observers blind to which DNA constructs were electroporated scored the presence or absence of aberrant RGC projections at the chiasm.

Ex vivo retinal electroporation. E13.5 and E14.5 embryos were removed from anesthetized mothers by cesarean section and decapitated. Graduated pulled-glass micropipettes were filled with a DNA solution $(0.4$ $\mu \mathrm{g} / \mathrm{ml} \mathrm{GFP}$ in the absence or presence of $3.0 \mu \mathrm{g} / \mathrm{ml} \mathrm{HA-EphB} \mathrm{DNA} \mathrm{plus}$ $0.03 \%$ Fast Green Dye in distilled water). Heads were pinned down dorsal side up in a Petri dish containing PBS, and DNA was injected into the peripheral dorsal region (between the RPE and outer retinal layer) of both retinae. As above, tweezer-type electrodes were then placed around the head (with + electrode on the ventral surface of the head), and four $50 \mathrm{~ms}, 40 \mathrm{~V}$ square current pulses were delivered. Intact retinae were then removed and incubated in serum-free medium (SFM) derived from freshly bubbled (95\% oxygen $/ 5 \%$ carbon dioxide) DMEM/F-12 medium at $37^{\circ} \mathrm{C}$ for $40 \mathrm{~h}$, allowing for RGC differentiation and exogenous protein expression. Retinae were scanned for $\mathrm{GFP}^{+}$regions, which were then dissected out and prepared into explants. In some samples, a small DiI crystal was placed in the peripheral ventral crescent to ensure that the $\mathrm{GFP}^{+}$region was, in fact, peripheral dorsal retina (data not shown). Explants were plated either on laminin-coated dishes for live staining or plated adjacent to ephrin-B2-Fc or Fc borders and incubated overnight at $37^{\circ} \mathrm{C}$.

RGC explant assays and analysis. Preparation of retinal explant cultures, border assays, and analyses has been described in detail previously (Petros et al., 2006). For border assays, murine ephrin-B2-Fc (gift from 

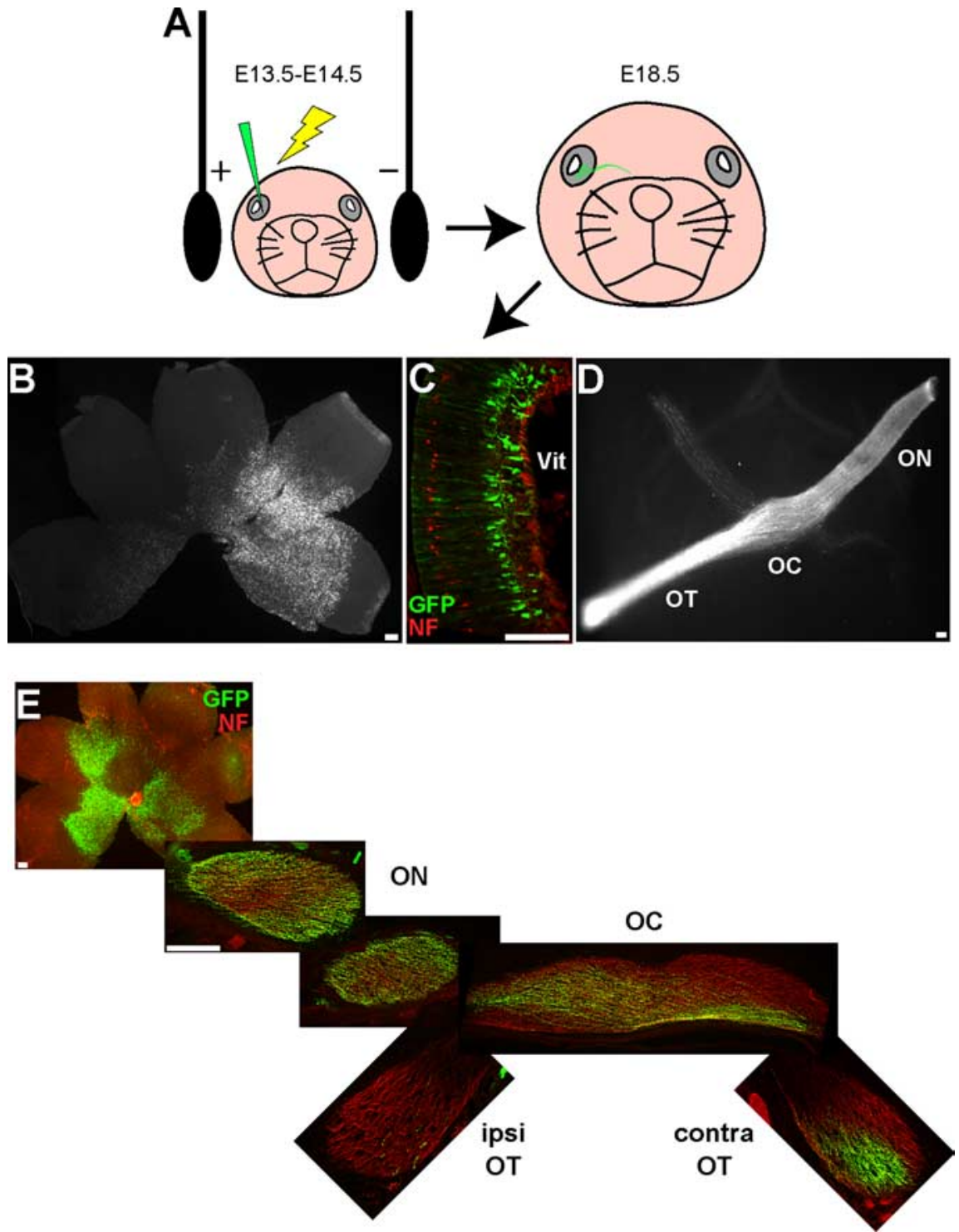

Figure 1. GFP expression in RGCS after in utero retinal electroporation. $\boldsymbol{A}$, Diagram depicting in utero retinal electroporation procedure. All images are taken from E18.5 embryos electroporated with GFP at E14.5. B, C, GFP ${ }^{+}$retinal cells are clearly visible in both whole-mount $(\boldsymbol{B})$ and cryosectioned $(\boldsymbol{C})$ retina, where the GFP ${ }^{+}$cells are predominantly localized to the ganglion cell layer. $\boldsymbol{D}, \boldsymbol{E}, \mathrm{GFP}{ }^{+}$axons can be visualized throughout the optic nerve (ON), optic chiasm (OC), and OT in either the semi-intact visual system preparation $(\boldsymbol{D})$ or serial cryosections throughout the projection pathway $(\boldsymbol{E})$. NF, Neurofilament; Vit, vitreous; ipsi, ipsilateral; contra, contralateral. Scale bars, $100 \mu \mathrm{m}$.

N. Gale, Regeneron, Tarrytown, NY) or human Fc (Jackson Immunologicals) was clustered by the addition of 10-fold excess goat anti-human Fc antibody (Jackson Immunologicals) at $37^{\circ} \mathrm{C}$ for $2 \mathrm{~h}$. To visualize borders, BSA conjugated to Alexa Fluor 555 (1:800; Invitrogen) was added to the Fc protein solutions, $100 \mu \mathrm{l}$ was applied to half of the culture dish and incubated at $37^{\circ} \mathrm{C}$ for $2 \mathrm{~h}$, and the entire dish was coated with laminin. Explants were plated in SFM containing 0.4\% methylcellulose (Sigma). For border assay analyses, a ratio of "area of $\mathrm{GFP}^{+}$signal within border region/total $\mathrm{GFP}^{+}$signal approaching border" was determined (Petros et al., 2006; Lee et al., 2008) (see Fig. 7, diagram).

Immunohistochemistry. E18.5 whole retinae and cryosections were blocked in 10\% normal donkey serum (NDS; Jackson Immunochemicals) plus $0.2 \%$ Triton X-100 (Sigma), whereas retinal explants from ex vivo electroporations were blocked in 10\% NDS plus $0.1 \%$ Tween (Sigma). The following primary antibody dilutions were used in these experiments, incubated in $50 \%$ block overnight at $4^{\circ} \mathrm{C}$ : rabbit anti-GFP, 1:500 (Invitrogen); sheep anti-GFP, 1:250 (Biogenesis); rat anti-HA, 1:500 (Roche); mouse IgG anti-neurofilament (2H3), 1:5 (gift from T.
Jessell, Columbia University); rabbit anti-Zic2, 1:10,000 (gift from S. Brown, University of Vermont, Burlington, VT). After $\geq 1 \mathrm{~h}$ PBS washes, appropriate fluorescent-conjugated secondary antibodies (Jackson Immunologicals) were added at room temperature for $\geq 2 \mathrm{~h}$.

For immunohistochemistry of live cells, ex vivo electroporated explants were cultured for $20 \mathrm{~h}$ at $37^{\circ} \mathrm{C}$. Dishes were washed twice with room-temperature HEPES buffer (HBS), and rat anti-HA (1:250) in HBS was added to each dish for $40 \mathrm{~min}$ at room temperature. Dishes were then washed several times with HBS, fixed with 4\% PFA, and stained for GFP, neurofilament, and HA (secondary antibody only) as described above. Fluorescence intensity and exposure time were kept constant between different experiments for imaging of live stained $\mathrm{HA}^{+}$ RGC axons and growth cones.

Retinal whole mounts, cryosections, and retinal explants were imaged on a Zeiss Axioplan 2 epifluorescent microscope equipped with AxioCam cameras (Zeiss) with Openlab deconvolution software (Improvision).

Analysis and statistics. All data were analyzed, and graphs were constructed using Openlab imaging software or Microsoft Excel. All error bars represent SEM, and statistical analysis was determined using Fisher's exact test, two-tailed Student's $t$ tests, or ANOVA followed by modified $t$ tests, where appropriate.

\section{Results}

Ectopic EphB1 expression converts crossed RGCs into an ipsilateral fate EphB1 is required for formation of the mature ipsilateral RGC projection from VT retina (Williams et al., 2003), but is EphB1 sufficient to direct RGC fibers ipsilaterally? We introduced genes into embryonic RGCs via in utero retinal electroporation (Garcia-Frigola et al., 2007) to determine whether ectopic EphB1 expression can convert non-VT RGC fibers to an ipsilateral fate. To confirm the viability of this technique, we electroporated GFP expression constructs into E14.5 retina and harvested the embryos at E18.5 (Fig. $1 \mathrm{~A}$ ). We chose E14.5 because this is when the ipsilateral projection begins to form (Petros et al., 2008). GFP is visible in RGC cell bodies (Fig. $1 B, C$ ) and axons within the optic nerve, chiasm, and OT, as viewed in either semiintact visual system preparations (Fig. 1D) or cryosections through the optic pathway (Fig. $1 E$ ). GFP ${ }^{+}$RGCs were usually confined to the central retina, and any retinae with $\mathrm{GFP}^{+}$cells in the VT retina were not included in the calculations. No obvious cell morphology or projection defects were observed in the retina or ventral diencephalon in GFP electroporated embryos.

To determine whether exogenous EphB1 can convert crossed RGC projections to an uncrossed fate, we coelectroporated GFPand HA-tagged EphB1 constructs into non-VT RGCs. GFP and HA were colocalized in the majority of RGCs (Fig. 2A), indicating that GFP reliably represents ectopic EphB1 expression. Examination of semi-intact whole-mount preparations revealed that ectopic EphB1 expression induced projection errors at the optic chiasm. In the majority of embryos electroporated with GFP plus 
A
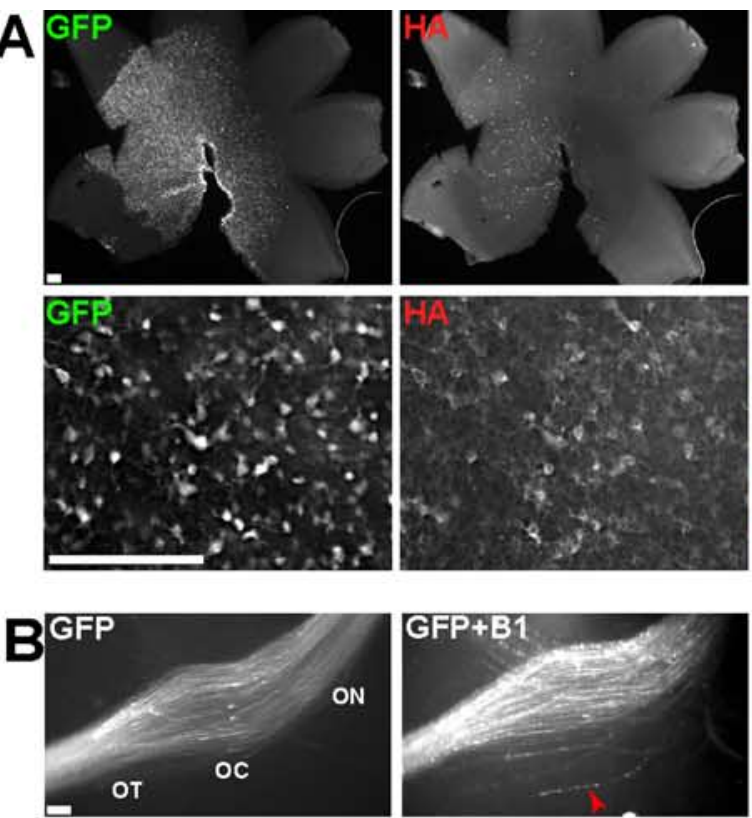

C

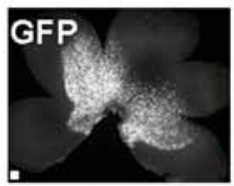

Ipsilateral OT
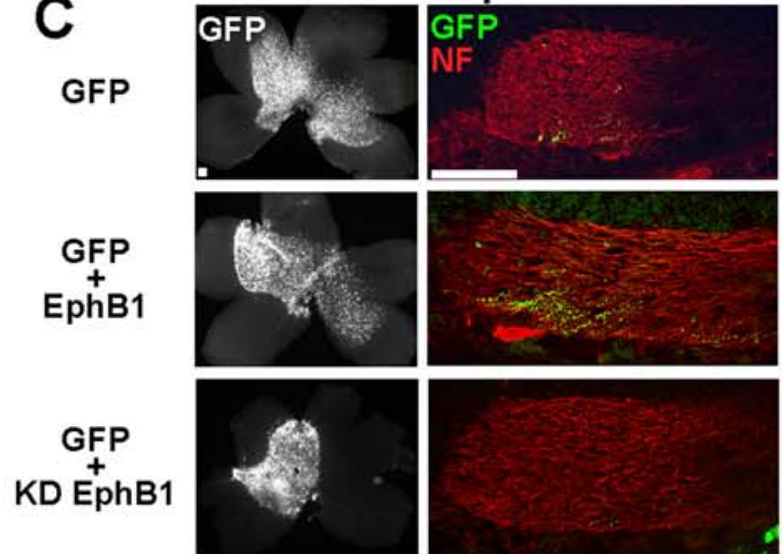

$\underset{+}{\text { GFP }}$
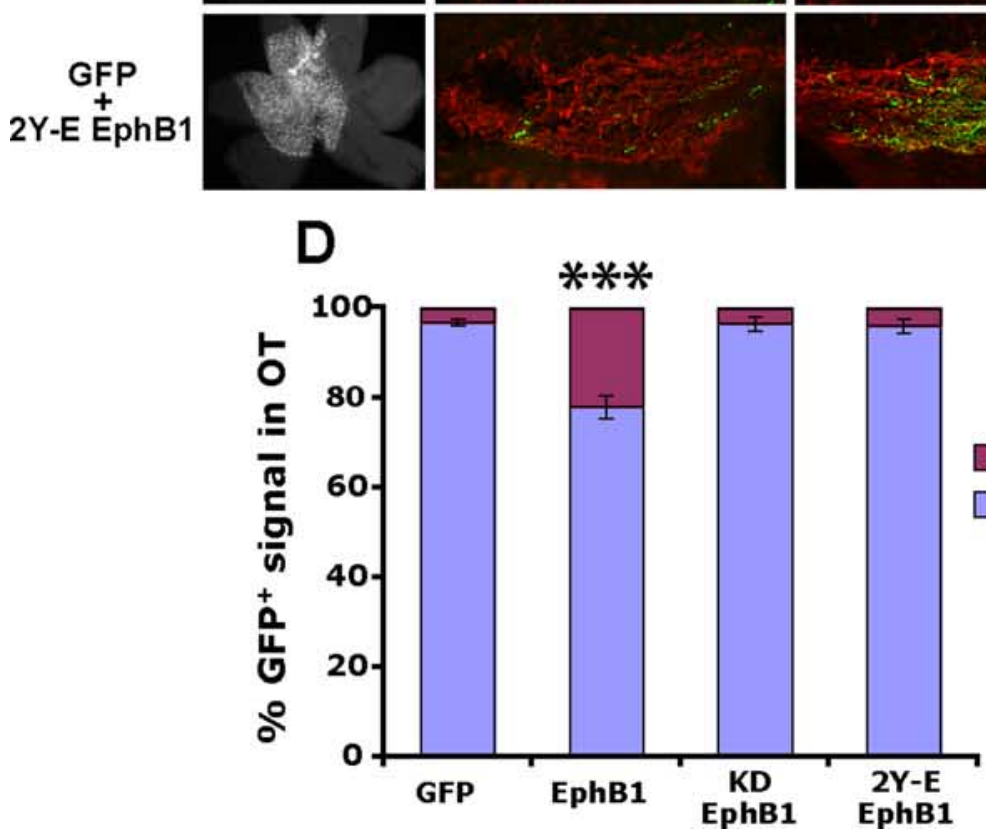

Figure 2. Ectopic EphB1 expression converts crossed RGC projections to an ipsilateral fate in a kinase-dependent manner. $\boldsymbol{A}$, Examples of E18.5 retina electroporated with GFP plus HA-EphB1 at E14.5. Top, Low-power view of entire retina. Bottom, Higher-power images demonstrating that the vast majority of GFP ${ }^{+}$cells are also $\mathrm{HA}^{+}$, indicating that GFP faithfully recapitu-
EphB1 (77\%; $n=13$ embryos), a small subset of $\mathrm{GFP}^{+}$axons displayed ectopic projections posterior to the chiasm (Fig. $2 B)$. This behavior was rarely observed after electroporating retina with GFP alone (14\%; $n=7 ; p=0.017$, Fisher's exact test).

We cryosectioned $\mathrm{GFP}^{+}$E18.5 heads through the optic chiasm and OTs to more clearly analyze $\mathrm{GFP}^{+}$projections (supplemental Fig. 1 available at www.jneurosci. org as supplemental material). Electroporation of GFP alone ( $n=14$ embryos) revealed that the majority of $\mathrm{GFP}^{+}$fibers from non-VT retina cross the midline and project into the contralateral OT, with only a small percentage $(3.3 \%)$ projecting ipsilaterally. In contrast, embryos electroporated with GFP and EphB1 $(n=17)$ displayed a significantly higher percentage of $\mathrm{GFP}^{+}$projections into the ipsilateral OT (22.1\%) (Fig. 2C,D).

This apparent increase in $\mathrm{GFP}^{+}$ipsilateral projections could arise from a decrease in contralateral projections. To investigate this possibility, we divided the amount of GFP signal in the ipsilateral OT by the area of $\mathrm{GFP}^{+}$cells in the retina. If there were an increase in $\mathrm{GFP}^{+}$ipsilateral projections, then this ratio should be higher for embryos electroporated with GFP and EphB1 compared with GFP alone. Indeed, this is what we observed (Fig. 3), indicating that there are definitively more $\mathrm{GFP}^{+}$axons in the ipsilateral OT of embryos electroporated with GFP plus EphB1. Thus, in addition to inducing misrouting at the chiasm, ectopic expression of EphB1 is sufficient to convert a subset of RGC projections from a crossed to an uncrossed fate.

To confirm that the increase in $\mathrm{GFP}^{+}$ ipsilateral projections is attributable to EphB1 activity, we prepared two constructs with perturbed EphB1 signaling: a

\footnotetext{
$\leftarrow$

lates ectopic EphB1 expression. $\boldsymbol{B}$, The optic chiasm (OC) in semi-intact visual system preparations of embryos electroporated with GFP (left) or GFP plus EphB1 (middle and right). Note that some GFP ${ }^{+}$axons from GFP plus EphB1 electroporated embryos misproject posteriorly at the optic chiasm (red arrowheads), which was rarely observed in embryos electroporated with GFP alone. $n \geq 7$ for each condition. $0 \mathrm{~N}$, 0 tic nerve. C, Whole-mount retina and cryosections through the ipsilateral and contralateral $0 \mathrm{Ts}$ from embryos electroporated with GFP, EphB1, KD EphB1, and 2Y-E EphB1. D, A significant increase in GFP ${ }^{+}$ipsilateral (Ipsi) projections is observed in embryos electroporated with GFP plus EphB1 compared with GFP alone (22 vs 3\%). This increase is not observed in KD EphB1 or 2Y-EEphB1 electroporated embryos. $n \geq 9$ embryos for each condition, from three or more separate electroporation experiments. Contra, Contralateral. Data represent mean \pm SEM. Scale bars, $100 \mu \mathrm{m}$. ANOVA: $F_{(3,48)}=27.09$, $p<0.0001$; modified $t$ tests: ${ }^{* * *} p<0.0001$.
} 

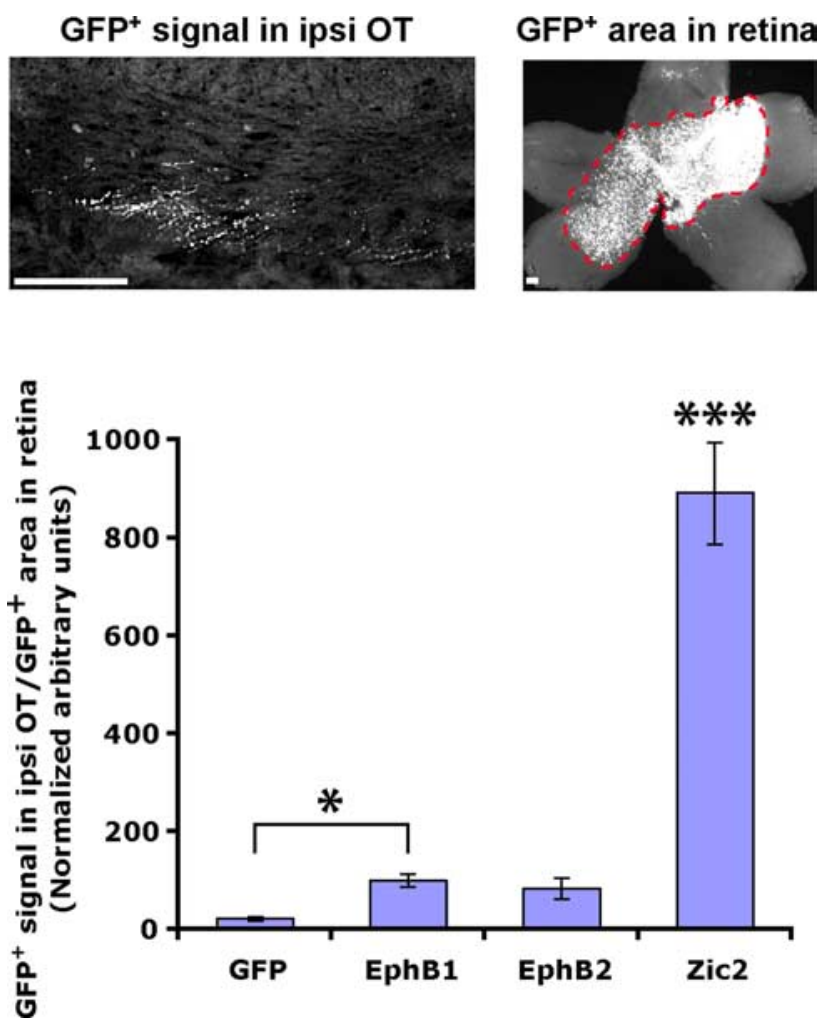

Figure 3. Ectopic EphB1 and Zic2 induce an increase in GFP ${ }^{+}$fibers in the ipsilateral $0 \mathrm{~T}$. It is possible that the apparent increase in ipsilateral projections actually arises from a decrease in contralateral projections. To confirm that this is not the case, we divided the GFP ${ }^{+}$signal in the ipsilateral $0 \mathrm{O}$ (ipsi 0T) by the GFP ${ }^{+}$area in the retina. If there is not an actual increase in uncrossed fibers, then this ratio should remain constant for all conditions. However, itis clear that there are significantly more $\mathrm{GFP}^{+}$axons in the ipsilateral 0 T of EphB1 and Zic2 electroporated embryos. $n \geq 10$ embryos for each condition, from three or more electroporation experiments. Data represent mean \pm SEM. Scale bars, $100 \mu \mathrm{m}$. ANOVA: $F_{(3,68)}=112.10, p<0.0001$; modified $t$ tests: ${ }^{*} p \leq 0.05,{ }^{* * *} p<0.0001$.

KD EphB1 and a construct in which the kinase domain remains active but the receptor is incapable of activating many downstream signaling cascades because of phospho-mimetic mutations of two JM tyrosine residues (2Y-E EphB1) (Zisch et al., 2000; Elowe et al., 2001; Vindis et al., 2003; Egea et al., 2005). Embryos electroporated with either GFP plus KD EphB1 $(n=11)$ or GFP plus 2Y-E EphB1 $(n=10)$ did not display an increase in $\mathrm{GFP}^{+}$ipsilateral fibers, mimicking control GFP electroporations (Fig. 2C,D). These findings indicate that the increased percentage of $\mathrm{GFP}^{+}$ipsilateral RGC axons after EphB1 electroporations is not an artifact of ectopic gene overexpression. In addition, these experiments demonstrate that EphB1 kinase activity and downstream signaling cascades are required to redirect RGC projections ipsilaterally in vivo.

\section{EphB1 is not as efficient as Zic2 in driving the ipsilateral RGC projection}

Although exogenous EphB1 redirects a significant percentage of $\mathrm{GFP}^{+}$fibers into the ipsilateral OT, the majority of $\mathrm{GFP}^{+}$axons still project contralaterally. It is possible that some EphB1 ${ }^{+}$axons arrive at the optic chiasm after ephrin-B2 has been downregulated, which occurs at E16.5 (Williams et al., 2003), and thus EphB1 ${ }^{+}$axons can project through the ephrin-B2-negative optic chiasm. If this is true, then electroporating EphB1 $1 \mathrm{~d}$ earlier at E13.5 should produce an even greater increase in the percentage of $\mathrm{GFP}^{+}$ipsilateral fibers. However, we did not observe an additional increase in the number of $\mathrm{GFP}^{+}$ipsilateral projections when EphB1 was electroporated at E13.5 $(n=13)$ (Fig. 4), indicating that ectopic introduction of EphB1 may be capable of converting only $\sim 20 \%$ of all RGCs to an ipsilateral fate.

Exogenous EphB1 may not be capable of overriding endogenous transcriptional programs that direct the contralateral RGC projection. Similar to EphB1, the transcription factor Zic2 is expressed in the VT crescent and is required for directing the ipsilateral projection (Herrera et al., 2003). Zic2 drives EphB1 expression (Garcia-Frigola et al., 2008; Lee et al., 2008), and ectopic Zic2 delivery can convert contralateral projections into an ipsilateral fate (albeit only when delivered at E13.5 and not E14.5) (Garcia-Frigola et al., 2008). To directly compare the abilities of EphB1 and Zic2 to redirect RGC fibers ipsilaterally, we electroporated GFP plus Zic2 into E13.5 retina $(n=10)$. The majority of $\mathrm{GFP}^{+}$RGCs coexpress Zic2 (Fig. 4A). In agreement with previous data (Garcia-Frigola et al., 2008), we found that exogenous Zic2 redirected nearly $50 \%$ of $\mathrm{GFP}^{+}$RGC projections ipsilaterally (Figs. 3, 4 B, C). Thus, Zic2, located upstream of EphB1 in the hierarchy of genes that controls the ipsilateral program, is more efficient at driving RGC fibers to an ipsilateral fate than EphB1 alone.

\section{Receptor specificity is more important than net EphB} receptor levels for RGC axon divergence at the optic chiasm EphB2 is expressed in a high ventral-to-low dorsal gradient, and EphB3 is homogenously expressed within the RGC layer as the uncrossed RGC pathway develops (Birgbauer et al., 2000; Williams et al., 2003; McLaughlin and O'Leary, 2005). Thus, RGCs within the VT crescent likely express all three EphB receptors. Murine EphB1 and EphB2 sequences are highly similar ( 75\% identical), and both have similar binding affinities to ephrin-B2 (Bergemann et al., 1995; Brambilla et al., 1996; Gale et al., 1996). Whereas $E p h B 1^{-1-}$ mice have a severely reduced ipsilateral projection, axon divergence at the optic chiasm appears normal in $E p h B 2^{-/-}, E p h B 3^{-I-}$, and $E p h B 2^{-/-} ; E p h B 3^{-/-}$mice (Williams et al., 2003) [although EphB2 ${ }^{-1-} ; E p h B 3^{-1-}$ mice display intraretinal guidance errors (Birgbauer et al., 2000)].

One possibility, which is consistent with the current data (Williams et al., 2003), is that EphB1 expression in the VT retina increases the total EphB receptor level (EphB1 plus EphB2 plus EphB3) above a certain threshold, which in turn could drive RGC fibers into the ipsilateral OT (Fig. 5A). Thus, the absolute level of EphB receptors may control retinal axon divergence at the optic chiasm, similar to the retinocollicular projection (Brown et al., 2000; Lemke and Reber, 2005). To address this hypothesis, we introduced HA-tagged EphB2 into embryonic RGCs via in utero retinal electroporation $(n=13)$ (Fig. $5 B)$. If the total EphB receptor levels drive the ipsilateral projection, then we would expect to see a similar level of $\mathrm{GFP}^{+}$ipsilateral projections compared with EphB1. However, ectopic EphB2 expression produced a significantly weaker increase in $\mathrm{GFP}^{+}$ipsilateral RGC projections (10.0\%) compared with EphB1 (22.3\%) (Figs. 3, 5C,D). Thus, EphB2 is less efficient in redirecting RGC projections ipsilaterally compared with EphB1.

This effect could arise from weaker expression levels of EphB2 compared with EphB1. To examine surface expression levels of EphB1 and EphB2, we developed a novel ex vivo retinal electroporation technique to efficiently introduce GFP plus EphB1/B2 into peripheral dorsal RGCs $\left(\mathrm{EphB1}{ }^{-} / \mathrm{EphB}^{-}\right.$) and prepare $\mathrm{GFP}^{+}$explants from these retina (Fig. 6A) (see Materials and Methods). This approach allows for greater control of injection sites compared with in utero electroporation. After culturing $\mathrm{GFP}^{+}$retinal explants for $20 \mathrm{~h}, \alpha$-HA antibody was bath applied 
to live explants to label HA-tagged EphB proteins on the cell surface. Surprisingly, HA immunostaining was consistently more intense on EphB2 electroporated RGC axons compared with fibers from EphB1 electroporated explants (Fig. 6B). Thus, EphB1 is more efficient at inducing an ipsilateral RGC projection compared with EphB2, even though exogenous EphB2 is expressed at higher surface levels on individual neurons.

The stronger EphB2 expression levels could stimulate EphB2 kinase activity, potentially desensitizing these EphB2 ${ }^{+}$axons to ephrin-B2. To examine this possibility, we plated $\mathrm{GFP}^{+}$dorsal retinal explants adjacent to ephrin-B2 or control Fc border substrates (Petros et al., 2006) (Fig. 6A). As expected, GFP ${ }^{+}$axons electroporated with GFP and GFP plus KD EphB1 were not repelled by ephrin-B2 substrates, whereas $\mathrm{GFP}^{+}$axons from EphB1 electroporated explants were repelled at ephrin-B2 borders (Fig. 7). RGC axons electroporated with GFP plus EphB2 also displayed strong repulsion after contacting ephrin-B2 substrates (Fig. 7 ), indicating that exogenous EphB2 ${ }^{+}$ RGCs are still capable of responding to ephrin-B2 in vitro, even when expressed at very high surface levels.

Several conclusions can be drawn from this series of experiments. First, EphB1 is significantly more efficient than EphB2 in converting crossed RGC fibers to an ipsilateral fate. Second, because EphB2 is expressed at higher surface levels, the specific EphB receptor subtype (EphB1) is more important for driving the ipsilateral projection than the net EphB receptor expression levels. Thus, certain features of the EphB1 receptor allow it to more efficiently direct RGC fibers to an ipsilateral fate.

The extracellular and JM domains of EphB1 are required for maximal efficiency in driving the uncrossed projection

Very few studies have examined different domains and signaling capabilities between EphB1 and EphB2, and rarely (if ever) has this been examined in vivo. One report indicated that the adaptor protein Grb7 might interact specifically with EphB1 (at tyrosine 928) and not with other EphB receptors (Han et al., 2002). Grb7 is activated after netrin-1 stimulation (Tsai et al., 2007), indicating that Grb7 may be involved in axon guidance decisions. We electroporated an EphB1 construct with a mutated Grb7 interaction site (EphB1Y928F) into embryonic retina, but these embryos displayed an increase in $\mathrm{GFP}^{+}$ipsilateral projections similar to wildtype (WT) EphB1 electroporations $(19.7 \% ; n=10$; data not
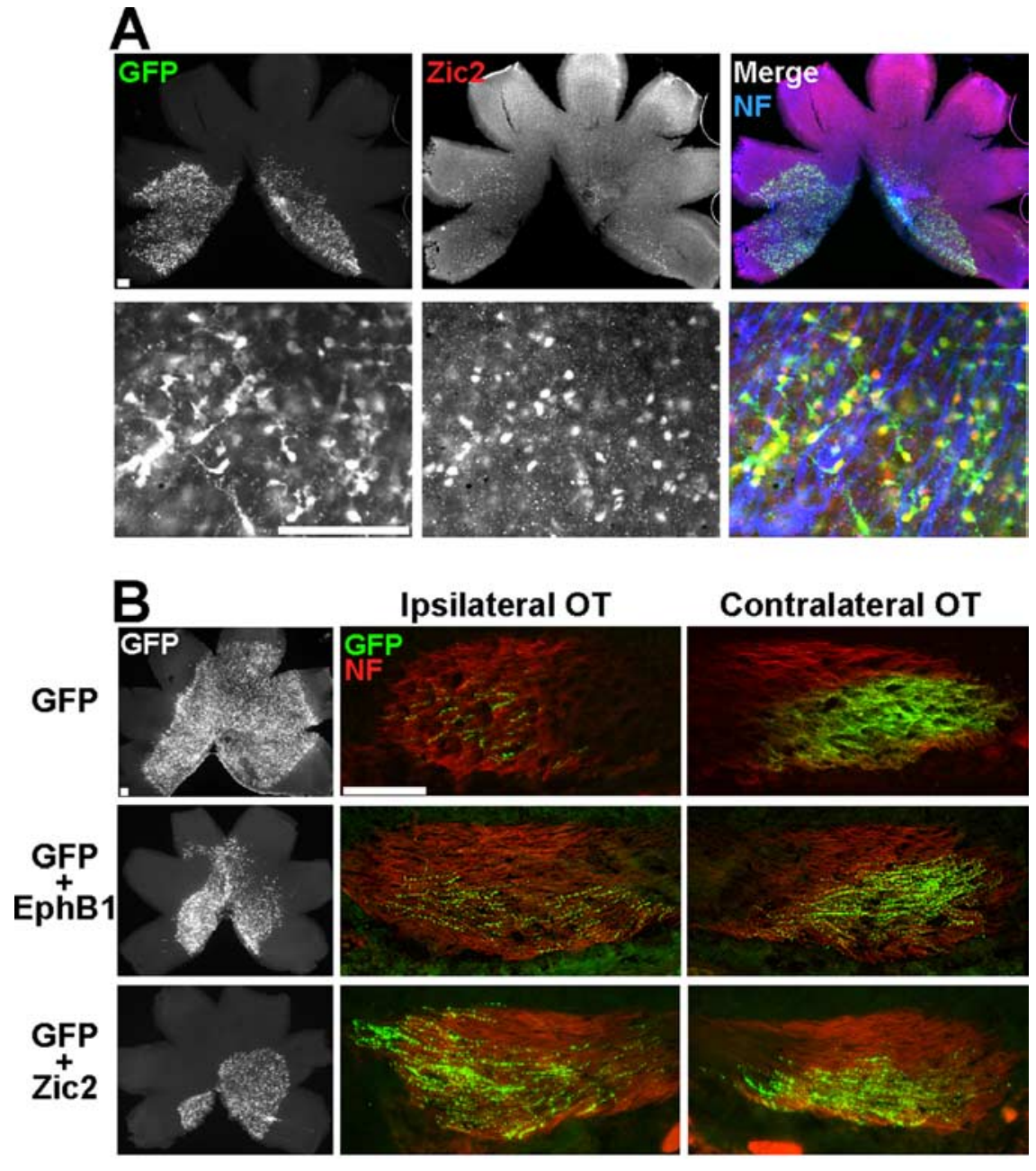

\section{Contralateral OT}
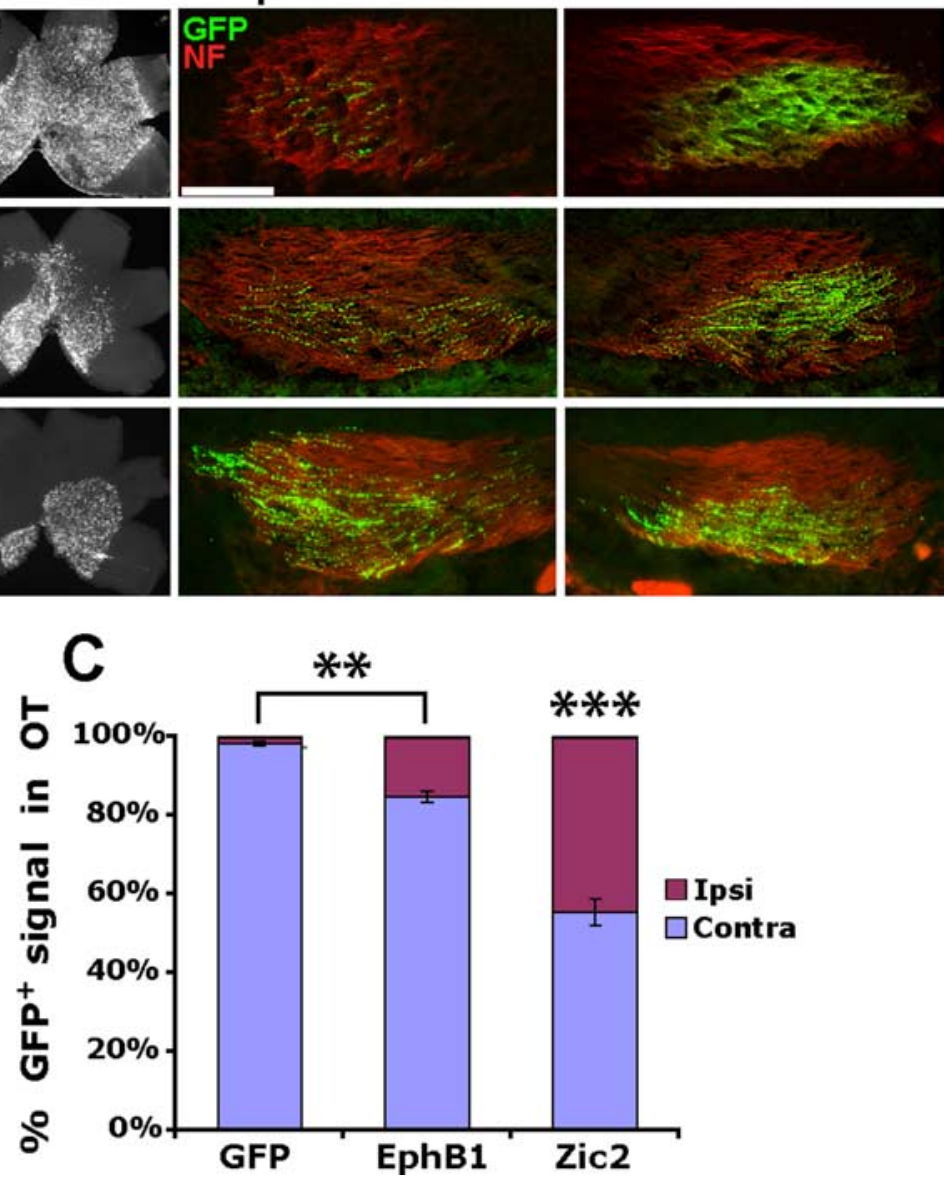

Figure 4. Zic2 induces a greater increase in ipsilateral RGC projections compared with EphB1. A, Low-power (top) and highpower (bottom) images of E18.5 retina electroporated with GFP plus Zic2 at E13.5. Note that the majority of GFP ${ }^{+}$cells stain positive for Zic2. B, Representative examples of E18.5 retina and OTs from embryos electroporated with GFP, GFP plus EphB1, and GFP plus Zic2 at E13.5. C, Whereas electroporating EphB1 at E13.5 did not induce a greater increase in GFP ${ }^{+}$ipsilateral (Ipsi) projections compared with E14.5 electroporations, ectopic Zic2 expression is significantly more efficient in converting contralateral (Contra) RGC projections to an ipsilateral fate. $n=5$ for GFP control electroporations and $n \geq 10$ for EphB1 and Zic2 electroporations, from three or more different electroporation experiments. Data represent mean \pm SEM. Scale bars, $100 \mu \mathrm{m}$. ANOVA: $F_{(2,25)}=71.28, p<0.0001$; modified $t$ tests: ${ }^{* *} p<0.005$, ${ }^{* * *} p<.0001$. NF, Neurofilament.

shown). Thus, this tyrosine residue (and Grb7 interaction site) is dispensable for RGC repulsion at the optic chiasm.

To further address the differences in efficiency between EphB1 and EphB2, we prepared chimeric receptors whereby the intracellular portion of EphB1 was replaced by EphB2 
A
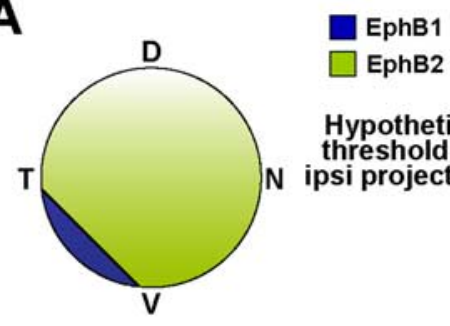

Hypothetical
threshold for ipsi projections
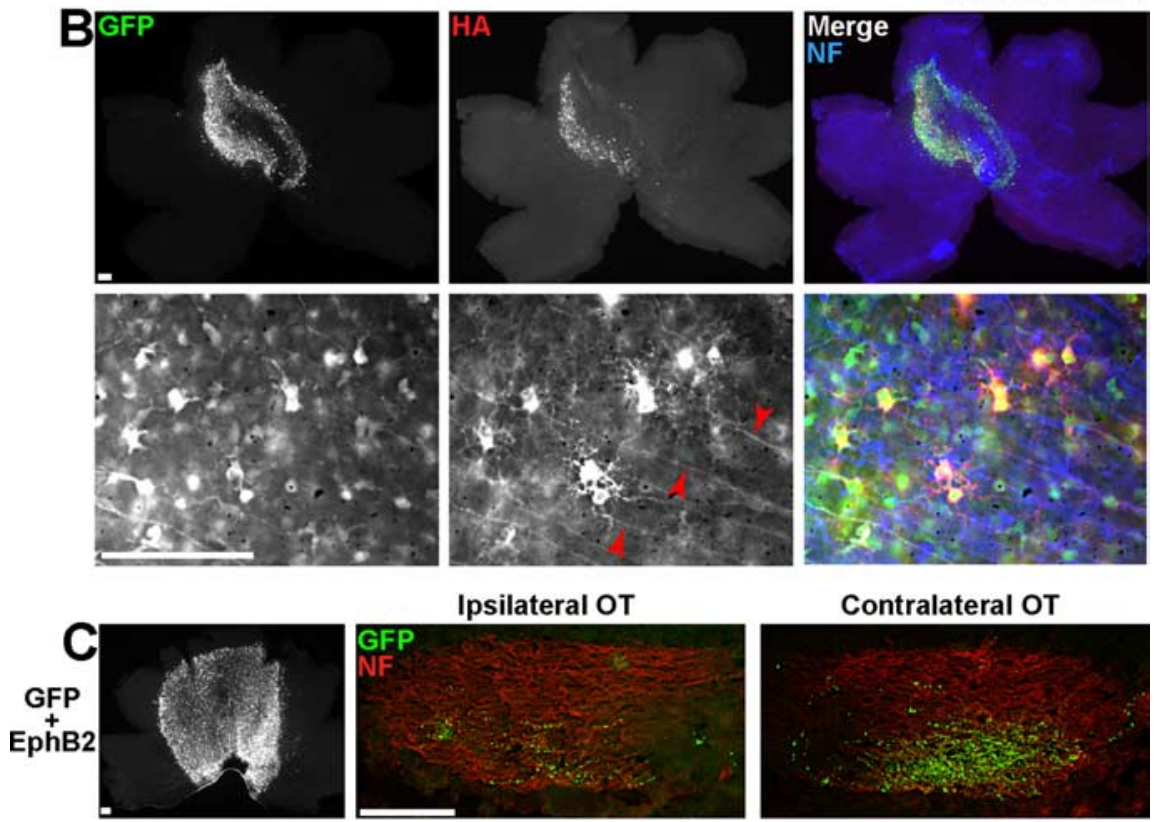

*

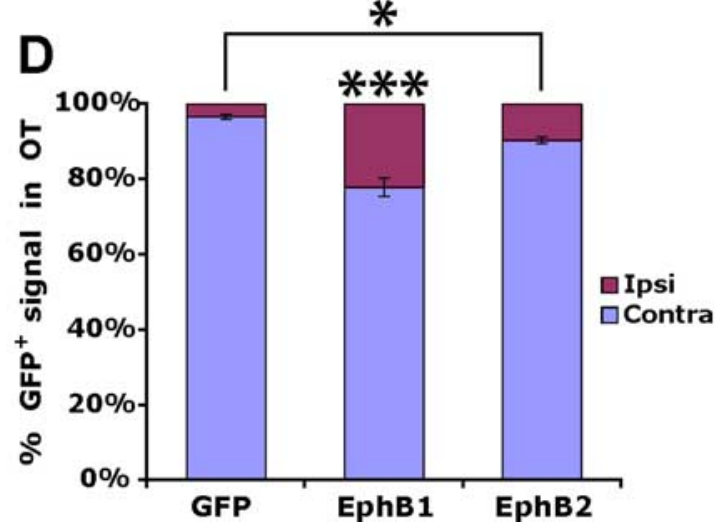

Figure 5. EphB1 induces a greater proportion of GFP ${ }^{+}$ipsilateral projections compared with EphB2. A, Diagram depicting expression patterns of EphB1 and EphB2 in the embryonic mouse retina. The graph represents a scenario, consistent with current data from EphB knock-out mice, in which the total expression level of EphB receptors exceeds a hypothetical threshold and drives the ipsilateral (ipsi) projection, rather than the specificity of EphB1. We tested whether ectopic expression of EphB2 in RGCs [EphB2 gain of function (B2-gof); right column] supports the validity of this model. WT, Wild type; D, dorsal; T, temporal; N, nasal; $V$, ventral. B, Low-power and high-power images of E18.5 retina electroporated with GFP plus EphB2 at E14.5. Of note, HA expression is visible on intraretinal $\mathrm{RGC}$ axons electroporated with $\mathrm{EphB2}$ (red arrowheads), but $\mathrm{HA}$ was rarely observed in $\mathrm{EphB1}{ }^{+}$axons (Fig. 2A). C, Representative example of retina and OTs electroporated with GFP plus EphB2. NF, Neurofilament. D, EphB1 is significantly more efficient at directing ipsilateral (Ipsi) projections compared with EphB2 (22 vs 10\%), but EphB2 does induce a greater percentage of uncrossed projections compared with GFP alone (10 vs $3 \%$ ). $n \geq 13$ embryos for each condition, from three or more separate electroporation experiments. Contra, Contralateral. Data represent mean \pm SEM. Scale bars, $100 \mu \mathrm{m}$. ANOVA: $F_{(2,41)}=31.52, p<0.0001$; modified $t$ tests: ** $p<0.05$, $^{* *} p<0.0001$.

(EphB1out-B2in), and vice versa (EphB2out-B1in). We hypothesized that one chimera would behave like EphB1 and the other like EphB2, revealing whether the differences in efficiency are attributable to the extracellular or intracellular domains. How- ever, both EphB1out-B2in $(n=14)$ and EphB2out-B1in $(n=17)$ induced a weak increase in the percentage of $\mathrm{GFP}^{+}$ipsilateral projections $(\sim 10 \%)$, similar to fulllength EphB2 (Fig. 8). Thus, neither chimeric receptor was capable of increasing ipsilateral projections as efficiently as WT EphB1, implying that portions of both the intracellular and extracellular domains are required for efficiently redirecting RGC axons ipsilaterally.

To further investigate this issue, we compared the EphB1 and EphB2 sequences and found that EphB2 ends in an IQSVEV motif, whereas EphB1 ends in SPSVMA (supplemental Fig. 2, available at www.jneurosci.org as supplemental material). The IQSVEV sequence of EphB2 is a postsynaptic density-95/Discs large/zona occludens-1 (PDZ)-binding motif (PBM) required for interaction with the $\mathrm{PDZ}$ domain of the ras-binding protein AF6 (Hock et al., 1998) and is important for clustering AMPA receptors at the synapse (Kayser et al., 2006). Although other EphB receptors have PBMs similar to EphB2 (Torres et al., 1996; Hock et al., 1998), the T6 residues of EphB1 are not predicted to be a PBM.

To determine whether the lack of a PBM underlies the functional differences between EphB1 and EphB2, we prepared chimeric receptors where the T6 residues were swapped (EphB1-B2T6 and EphB2B1T6). When electroporated into embryonic RGCs, EphB1-B2T6 ( $n=12)$ produced a strong increase in $\mathrm{GFP}^{+}$ ipsilateral projections, similar to EphB1, whereas EphB2-B1T6 $(n=10)$ produced a weaker increase in $\mathrm{GFP}^{+}$ipsilateral projections, similar to EphB2 (Fig. 8). Thus, the PBM (or lack thereof) does not give rise to the different effects of EphB1 and EphB2 at the optic chiasm.

Eph receptors interact with each other via the SAM domain when clustering into larger oligomers, and differences in clustering efficiencies may underlie the functional differences between EphB1 and EphB2 (Stein et al., 1998b). We prepared chimeric receptors where we swapped the terminal 300 residues, which include the PBM, SAM domain, and most of the kinase domains (EphB1-B2T300 and EphB2-B1T300). In addition, we prepared a truncated EphB1 receptor lacking a SAM domain (EphB1 $\triangle$ SAM). EphB1 $\triangle$ SAM $(n=12)$ produced an increase in $\mathrm{GFP}^{+}$ ipsilateral projections similar to full-length EphB1 electroporations (Fig. 8), indicating that the SAM domain is not required for driving crossed RGC fibers ipsilaterally. EphB1-B2T300 $(n=11)$ produced a large increase in uncrossed $\mathrm{GFP}^{+}$fibers, similar to EphB1, and EphB2-B1T300 ( $n=11)$ inducing a significantly weaker percentage of ipsilateral projections, similar to EphB2 (Fig. 8). 
The results of these chimera studies are summarized in Figure $8 B$. The EphB1 extracellular region is required for efficiently converting crossed fibers to an uncrossed fate. However, electroporation of the EphB1out-B2in construct produced only a weak increase in ipsilateral projections, indicating that simply having the EphB1 extracellular domain is not sufficient for maximal efficiency. Comparison of the EphB1out-B2in and EphB1out-B2T300 chimeras reveals that the EphB1 JM region is required for the higher efficiency of EphB1. However, the JM region is not the sole determinant, because EphB2out-B1 in (which includes the EphB1 JM region) produces a minor increase in ipsilateral projections (Fig. $8 \mathrm{~B}$ ). Thus, both the JM domain and the extracellular domain of EphB1 are required to most efficiently redirect RGC projections to an uncrossed fate.

\section{Discussion}

In this study, we demonstrate that ectopic EphB1 expression is sufficient to convert a significant proportion of crossed RGC projections to an uncrossed trajectory. Comparison of EphB1 and EphB2 revealed that the specific subtype of Eph receptor (EphB1) is more important than the total levels of EphB receptors in driving the ipsilateral projection. Additionally, we found that both the extracellular and JM domains of EphB1 are required to efficiently redirect RGC axons ipsilaterally. Thus, crossed RGC fibers can be converted to an ipsilateral fate by ectopic expression of EphB1 and EphB2 with varying degrees of efficiency (Fig. 9).

\section{Differences between EphB1 and EphB2} in driving the ipsilateral projection

EphB1 is significantly more efficient at redirecting RGC axons to an uncrossed fate compared with EphB2, even though EphB2 is expressed at higher surface levels in our experimental paradigm. Thus, the specific subtype of EphB receptor (in this case EphB1) is more important than net $\mathrm{EphB}$ receptor levels for driving RGC projections ipsilaterally. These results support the notion that EphB1 appears to be the sole EphB receptor that directs the mature ipsilateral projection (Williams et al., 2003), despite the presence of EphB2 and EphB3 in the peripheral VT retina.

It is possible that the differences in EphB1 and EphB2 surface levels are an artifact of exogenous overexpression. However, introduction of Zic2 into VT explants in vitro did not induce an additional increase in EphB1 expression (Lee et al., 2008), indicating that cellular mechanisms may prevent EphB1 from being expressed at high levels. Additionally, significant differences in EphB1 and EphB2 expression levels and cellular localization were also observed after electroporation into chick motor neurons (A. Kania, personal communication). Thus, RGCs may possess endogenous mechanisms to limit EphB1 expression levels.

We found that exogenous EphB1 ${ }^{+}$and EphB2 ${ }^{+}$RGC axons from dorsal explants displayed similar levels of repulsion to
ephrin-B2 substrates (Fig. 7), in contrast to their different effects in vivo. We repeated these border assays with lower ephrin-B2 substrate concentrations, but we were unable to identify ephrin-B2 concentrations at which repulsion was significantly different between EphB1 ${ }^{+}$and EphB2 ${ }^{+}$axons (data not shown). The lack of chiasm cells and "pro-crossing" molecules in the border substrate likely make this environment more repulsive than the optic chiasm. Similar contradictory findings were observed with the crossed RGC projection, whereby perturbing $\mathrm{Nr}$ CAM reduced neurite extension from dorsotemporal (DT) RGC axons in vitro, but DT RGC projections were unaffected in $\mathrm{Nr}$ $C A M^{-1-}$ mice (Williams et al., 2006). These observations emphasize that results obtained from in vitro models, while reductionist and precise, need to be validated in vivo.

Our results from the EphB1-EphB2 chimeric receptor electroporations reveal that both the EphB1 JM region and extracellular domain are required for EphB1 to most efficiently convert crossed RGC projections to an uncrossed fate. The JM region contains two tyrosine residues that are important interaction sites for numerous downstream signaling proteins (Pasquale, 2008). It is possible that certain proteins interact more efficiently 
A
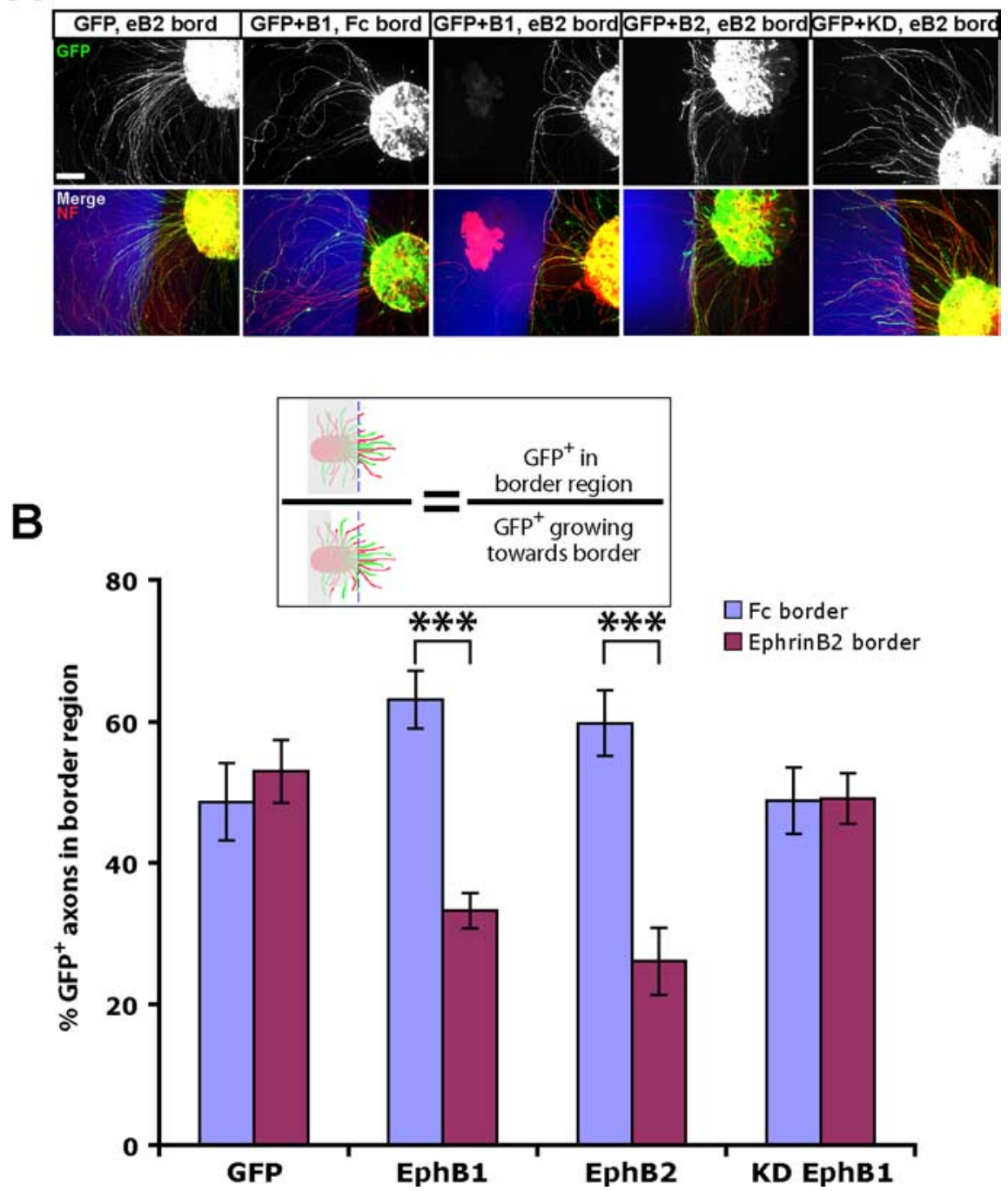

Figure 7. EphB2 electroporated retinal axons are repelled by ephrin-B2 substrates. $\boldsymbol{A}$, Examples of explants from ex vivo electroporated retina plated adjacent to ephrin-B2 (eB2) or control Fc substrate borders (blue regions; see Fig. 6). NF, Neurofila-

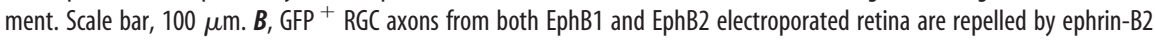
borders, whereas RGC axons electroporated with GFP alone or KD EphB1 project uninhibited into the ephrin-B2 region. The diagram depicts method of analysis, with GFP axons in the gray region not included in calculations. $n \geq 12$ explants for each condition, from at least two separate experiments. Data represent mean $\pm \mathrm{SEM}$. ANOVA: $F_{(7,127)}=8.08, p<0.0001$; modified t tests: ${ }^{* * *} p<0.0001$.

with ephrin-B2-bound EphB1 compared with ephrin-B2-bound EphB2. A previous study prepared chimeric receptors with the EphB extracellular domain joined to the intracellular TrkB domain. After stimulation with ephrin-B2, the EphB1-TrkB construct produced a functional response in the focus formation assay, whereas EphB2-TrkB lacked this response (Brambilla et al., 1996). Thus, EphB1 and EphB2 may have different signaling capabilities after ephrin-B2 binding despite their similar binding affinities to ephrin-B2.

Additionally, the conformation of the JM region is important for blocking kinase activity in the inactive form of the receptor (Wybenga-Groot et al., 2001), and various Eph receptor-ligand pairs undergo different dimeric or tetrameric architectural arrangements (Himanen et al., 2004). Thus, it is highly plausible that ephrin-B2 induces different conformational changes after binding EphB1 and EphB2 that could affect their ability to oligomerize and/or stimulate specific signaling components to interact with the JM domain.
EphB1 kinase activity is required for directing the ipsilateral projection, but the SAM domain is dispensable

Results from the KD EphB1 and 2Y-E EphB1 electroporations highlight the requirement for kinase activity and downstream signaling cascades in driving the ipsilateral RGC projection. Previous studies have identified numerous proteins that interact with the two JM phosphorylated tyrosine residues of Eph receptors, such as Src kinases, RasGAP, Nck, and the Rho GEF Vav2 (Stein et al., 1998a; Elowe et al., 2001; Vindis et al., 2003; Cowan et al., 2005; Pasquale, 2005). Of interest, several of these signaling cascades converge on Rac/Rho signaling, an important mechanism controlling growth cone behavior. It would be interesting for future studies to examine which of these downstream signaling cascades are required for ephrinB2-induced RGC growth cone repulsion at the optic chiasm. Additionally, there is some indication that the $2 \mathrm{Y}-\mathrm{E}$ mutation produces a constitutively active Eph receptor (Egea et al., 2005), and thus we cannot rule out that the inability of $2 \mathrm{Y}-\mathrm{E}$ EphB1 to reroute RGC fibers ipsilaterally arises from a constitutively active kinase domain.

Our results demonstrate that the SAM domain is dispensable for increasing the percentage of $\mathrm{GFP}^{+}$ipsilateral RGC fibers. It has been well documented that the SAM domain is important for Eph receptor dimerization (Pasquale, 2005), but overexpression of EphB1 $\Delta$ SAM might allow for ligand-bound EphB1 to transphosphorylate adjacent EphB1 receptors despite the absence of their primary dimerization interface. However, formation of the corticospinal tract, anterior commissure, and thalamocortical projections are essentially normal in EphA4 $\Delta$ SAM mutant mice (Kullander et al., 2001; Dufour et al., 2006). These observations, combined with our findings on EphB1 $\Delta$ SAM function at the chiasm, strengthen the necessity for a better understanding of the in vivo functional relevance of the SAM domain.

\section{Limitations on converting RGC projections to an} ipsilateral fate

Although ectopic EphB1 expression induces a significant increase in $\mathrm{GFP}^{+}$ipsilateral RGC fibers, the majority of EphB1 ${ }^{+} \mathrm{RGCs}$ cross the midline. One possibility is that some EphB1 ${ }^{+}$fibers reach the chiasm and cross the midline after downregulation of ephrin-B2 at E16.5 (Williams et al., 2003), but an additional increase in $\mathrm{GFP}^{+}$ipsilateral fibers was not observed when EphB1 was electroporated $1 \mathrm{~d}$ earlier at E13.5 (Fig. 4). A more likely explanation is that EphB1 ${ }^{+}$RGC axons that traverse the midline continue to express pro-crossing factors [possibly CAMs or Islet2-regulated genes (Pak et al., 2004; Williams et al., 2006)], and ectopic expression of EphB1 may not be sufficient to overcome these pro-crossing mechanisms. In support of this hypoth- 


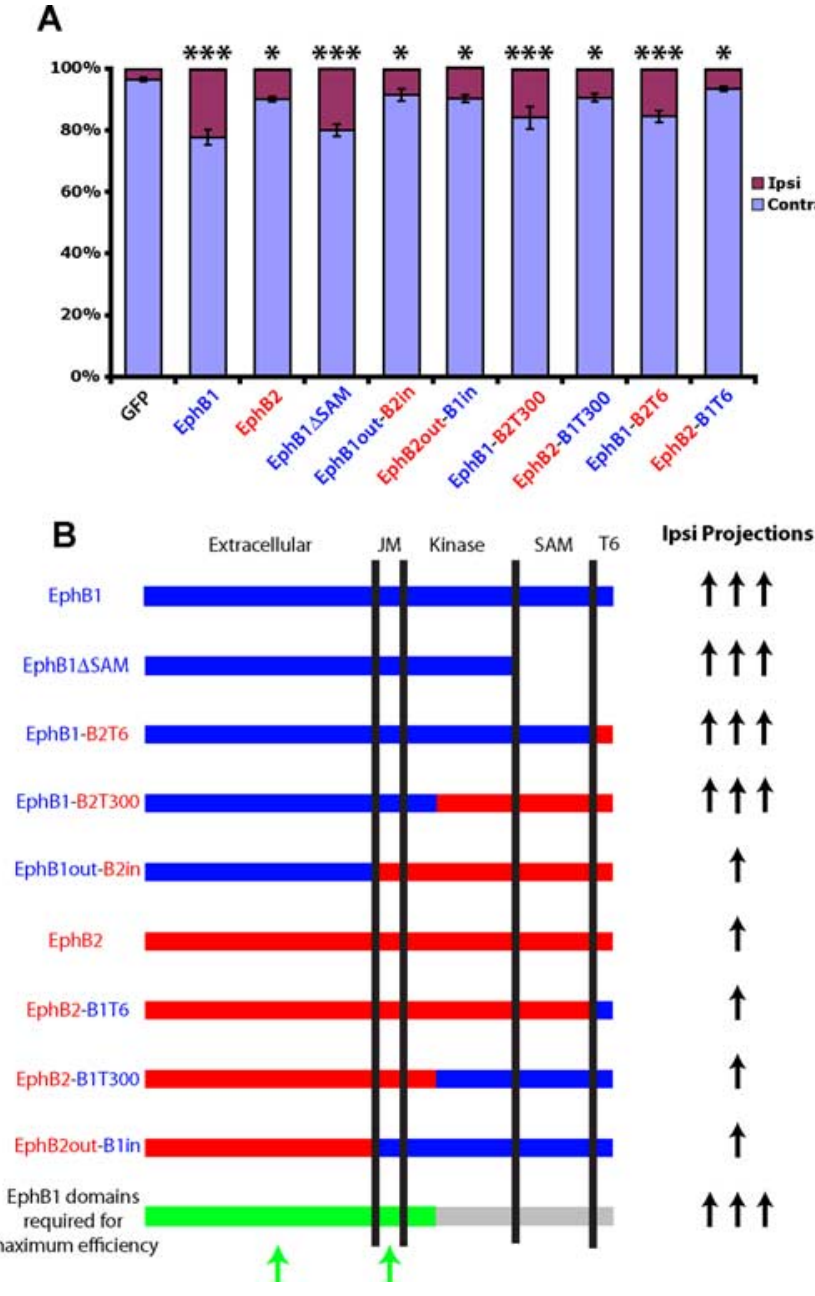

Figure 8. The extracellular and JM domains of EphB1 are required for maximum efficiency in rerouting RGC axons ipsilaterally. $A$, Graph displaying the percentages of GFP ${ }^{+}$ipsilateral (Ipsi) projections for GFP, EphB1, EphB2, EphB1 $\triangle$ SAM, and the chimeric EphB1-EphB2 receptor constructs. EphB1 regions are labeled blue, and EphB2 regions are labeled red. ${ }^{* *}$ Labeled columns are statistically identical, with all of these mutants having significantly higher GFP ${ }^{+}$ ipsilateral projections compared with GFP alone $(p<0.0001)$ and compared with labeled mutants $\left({ }^{*} p<0.05\right)$. [One exception is WT EphB1, which had a significantly higher percentage of $\mathrm{GFP}^{+}$uncrossed projections compared with EphB1-B2T300 and EphB1-B2T6 mutants ( $p<$ 0.05)]. *Labeled mutants are statistically identical, with all of these columns having significantly higher $\mathrm{GFP}^{+}$ipsilateral projections compared with GFP alone ( $p<0.05$, except for EphB2-B1T6, which is not significantly different from GFP) and a significantly lower GFP ${ }^{+}$ ipsilateral projections compared with labeled mutants $\left({ }^{* *} p<0.05\right)$. Contra, Contralateral. Data represent mean \pm SEM. ANOVA: $F_{(9,121)}=13.59, p<0.0001$. Scale bars, $100 \mu \mathrm{m} . \boldsymbol{B}$, Summary of EphB1 and EphB2 chimeric constructs and their ability to convert crossed RGCs to an uncrossed fate. Both the JM region and a portion of the extracellular domain (green domains on bottom bar) are required for maximal efficiency in giving rise to ipsilateral (Ipsi) projections.

esis, we found that Zic2 converts a significantly higher percentage of axons to an ipsilateral fate (Fig. 9). Furthermore, Zic2 induces a small increase in ipsilateral projections when introduced into E13.5 retina of EphB1 ${ }^{-1-}$ mice (Garcia-Frigola et al., 2008). Thus, Zic2 is more potent in shifting the molecular balance of non-VT RGCs toward an ipsilateral trajectory, likely by downregulating pro-crossing factors and/or upregulating other proipsilateral factors besides EphB1 (Fig. 9).

Exogenous EphB1 may interact with endogenous ephrinBs, which are expressed in a high dorsal-to-low ventral gradient in embryonic RGCs (McLaughlin and O'Leary, 2005). Because many RGCs electroporated with EphB1 are in the dorsal

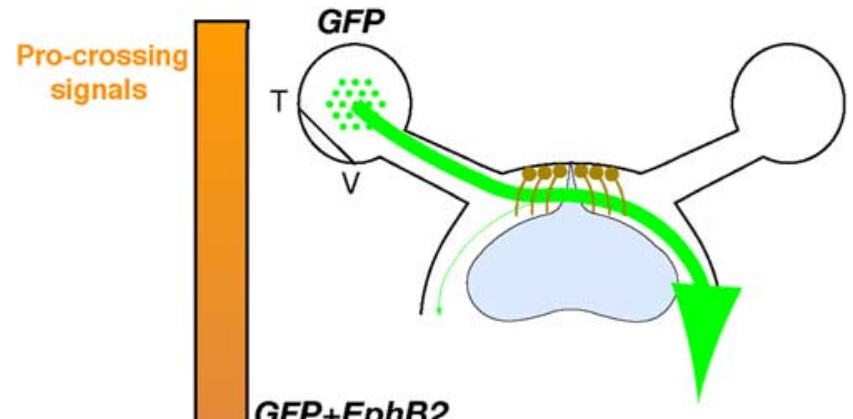

GFP+EphB2

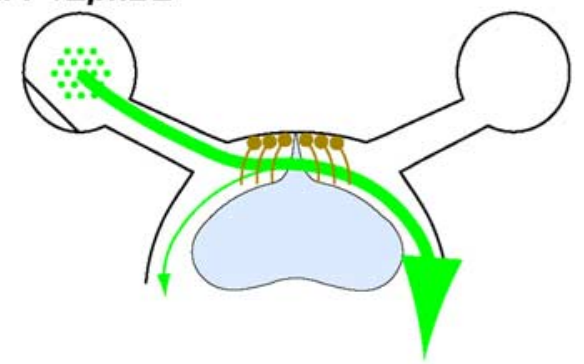

GFP+EphB1

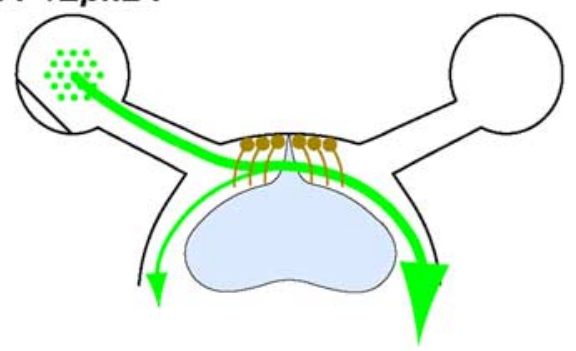

GFP+Zic2

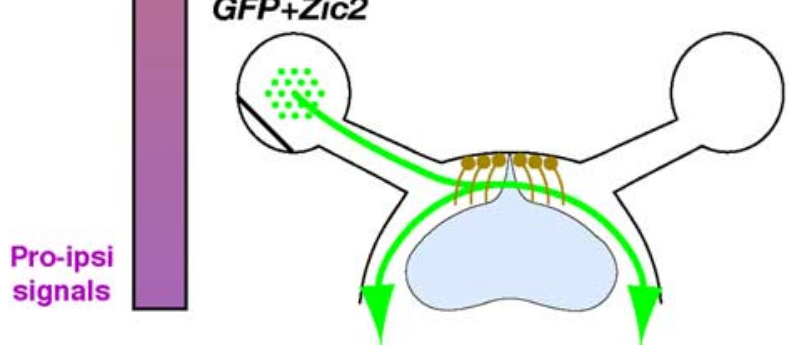

Figure 9. Effects of ectopic gene expression on retinal axon divergence at the optic chiasm. Diagrams summarize retinal fiber projection at the optic chiasm after ectopic expression of EphB1, EphB2, and Zic2 in non-VT RGCs. Nearly all GFP ${ }^{+}$axons cross the midline when GFP alone is electroporated into embryonic retina. A moderate increase in GFP ${ }^{+}$ipsilateral projections is observed in retina electroporated with GFP plus EphB2 ( 10\%), whereas RGCs electroporated with GFP plus EphB1 display an even greater increase in uncrossed GFP ${ }^{+}$fibers $(\sim 22 \%)$. The strongest effect is observed with Zic2, which is capable of converting $\sim 50 \%$ of non-VT GFP ${ }^{+}$RGC axons to an ipsilateral fate. The colored bar represents theoretical relative percentages of pro-crossing (orange) and "pro-ipsilateral" (Pro-ipsi; purple) signals in GFP ${ }^{+}$ RGCS. T, Temporal; V, ventral.

hemiretina, they likely express high levels of both EphB1 and ephrin-Bs. EphAs and ephrin-As interact in cis-when coexpressed in RGCs to modulate the function of EphA receptors (Hornberger et al., 1999; Carvalho et al., 2006). Conversely, EphAs and ephrin-As in motor neurons are localized to distinct membrane domains, preventing cis-interactions and enabling EphAs and ephrin-As to retain their individual functions (Marquardt et al., 2005). Whether EphB-ephrin-B interactions occur in cis in the retina to modulate EphB activity, or instead they segregate into distinct membrane domains, remains unknown. 


\section{Two roles for Eph-ephrin signaling in neural development}

Eph-ephrin interactions appear to have two prominent roles in axon guidance. First, Eph receptors and ephrins are often expressed as gradients in the origin and target region, as in the retinotectal pathway (McLaughlin and O'Leary, 2005) and thalamocortical projections (Vanderhaeghen et al., 2000; Dufour et al., 2003; Bolz et al., 2004; Cang et al., 2005). Proper topographic targeting in these systems is guided by the relative expression levels of Eph receptors and ephrins rather than the actual subtype of Eph receptor (Brown et al., 2000; Cang et al., 2005; Lemke and Reber, 2005; Torii and Levitt, 2005). Second, Ephephrin signaling is prominent at intermediate targets and decision regions, specifically at midline structures such as the optic chiasm (Williams et al., 2003), corpus callosum (Mendes et al., 2006), and spinal cord (Kadison et al., 2006; Kullander et al., 2001). Our results demonstrate that the specific subtype of Eph receptor, EphB1, is required for efficiently driving RGC projections ipsilaterally. Thus, in contrast to target regions, Eph receptor specificity trumps net Eph receptor levels at the optic chiasm. It will be important now to characterize functional differences between Eph receptors at other decision points, and to examine whether specific subtypes of Eph receptors or net Eph receptor levels guide these decisions.

\section{References}

Bergemann AD, Cheng HJ, Brambilla R, Klein R, Flanagan JG (1995) ELF-2, a new member of the Eph ligand family, is segmentally expressed in mouse embryos in the region of the hindbrain and newly forming somites. Mol Cell Biol 15:4921-4929.

Birgbauer E, Cowan CA, Sretavan DW, Henkemeyer M (2000) Kinase independent function of EphB receptors in retinal axon pathfinding to the optic disc from dorsal but not ventral retina. Development 127:1231-1241.

Bolz J, Uziel D, Muhlfriedel S, Gullmar A, Peuckert C, Zarbalis K, Wurst W, Torii M, Levitt P (2004) Multiple roles of ephrins during the formation of thalamocortical projections: maps and more. J Neurobiol 59:82-94.

Brambilla R, Bruckner K, Orioli D, Bergemann AD, Flanagan JG, Klein R (1996) Similarities and differences in the way transmembrane-type ligands interact with the Elk subclass of Eph receptors. Mol Cell Neurosci 8:199-209.

Brown A, Yates PA, Burrola P, Ortuno D, Vaidya A, Jessell TM, Pfaff SL, O'Leary DD, Lemke G (2000) Topographic mapping from the retina to the midbrain is controlled by relative but not absolute levels of EphA receptor signaling. Cell 102:77-88.

Cang J, Kaneko M, Yamada J, Woods G, Stryker MP, Feldheim DA (2005) Ephrin-as guide the formation of functional maps in the visual cortex. Neuron 48:577-589.

Carvalho RF, Beutler M, Marler KJ, Knoll B, Becker-Barroso E, Heintzmann R, Ng T, Drescher U (2006) Silencing of EphA3 through a cis interaction with ephrinA5. Nat Neurosci 9:322-330.

Cowan CW, Shao YR, Sahin M, Shamah SM, Lin MZ, Greer PL, Gao S, Griffith EC, Brugge JS, Greenberg ME (2005) Vav family GEFs link activated Ephs to endocytosis and axon guidance. Neuron 46:205-217.

Dufour A, Seibt J, Passante L, Depaepe V, Ciossek T, Frisen J, Kullander K, Flanagan JG, Polleux F, Vanderhaeghen P (2003) Area specificity and topography of thalamocortical projections are controlled by ephrin/Eph genes. Neuron 39:453-465.

Dufour A, Egea J, Kullander K, Klein R, Vanderhaeghen P (2006) Genetic analysis of EphA-dependent signaling mechanisms controlling topographic mapping in vivo. Development 133:4415-4420.

Eberhart J, Swartz M, Koblar SA, Pasquale EB, Tanaka H, Krull CE (2000) Expression of EphA4, ephrin-A2 and ephrin-A5 during axon outgrowth to the hindlimb indicates potential roles in pathfinding. Dev Neurosci 22:237-250.

Egea J, Nissen UV, Dufour A, Sahin M, Greer P, Kullander K, Mrsic-Flogel TD, Greenberg ME, Kiehn O, Vanderhaeghen P, Klein R (2005) Regulation of EphA4 kinase activity is required for a subset of axon guidance decisions suggesting a key role for receptor clustering in Eph function. Neuron 47:515-528.
Elowe S, Holland HJ, Kulkarni S, Pawson T (2001) Downregulation of the Ras-Mitogen-Activated protein kinase pathway by the EphB2 receptor tyrosine kinase is required for Ephrin-induced neurite retraction. Mol Cell Biol 21:7429-7441.

Flanagan JG, Vanderhaeghen P (1998) The ephrins and Eph receptors in neural development. Annu Rev Neurosci 21:309-345.

Gale NW, Holland SJ, Valenzuela DM, Flenniken A, Pan L, Ryan TE, Henkemeyer M, Strebhardt K, Hirai H, Wilkinson DG, Pawson T, Davis S, Yancopoulos GD (1996) Eph receptors and ligands comprise two major specificity subclasses and are reciprocally compartmentalized during embryogenesis. Neuron 17:9-19.

Garcia-Frigola C, Carreres MI, Vegar C, Herrera E (2007) Gene delivery into mouse retinal ganglion cells by in utero electroporation. BMC Dev Biol 7:103.

Garcia-Frigola C, Carreres MI, Vegar C, Mason C, Herrera E (2008) Zic2 promotes axonal divergence at the optic chiasm midline by EphB1dependent and -independent mechanisms. Development 135:1833-1841.

Han DC, Shen TL, Miao H, Wang B, Guan JL (2002) EphB1 associates with Grb7 and regulates cell migration. J Biol Chem 277:45655-45661.

Henkemeyer M, Itkis OS, Ngo M, Hickmott PW, Ethell IM (2003) Multiple EphB receptor tyrosine kinases shape dendritic spines in the hippocampus. J Cell Biol 163:1313-1326.

Herrera E, Brown L, Aruga J, Rachel RA, Dolen G, Mikoshiba K, Brown S, Mason CA (2003) Zic2 patterns binocular vision by specifying the uncrossed retinal projection. Cell 114:545-557.

Himanen JP, Chumley MJ, Lackmann M, Li C, Barton WA, Jeffrey PD, Vearing C, Geleick D, Feldheim DA, Boyd AW, Henkemeyer M, Nikolov DB (2004) Repelling class discrimination: ephrin-A5 binds to and activates EphB2 receptor signaling. Nat Neurosci 7:501-509.

Hock B, Bohme B, Karn T, Yamamoto T, Kaibuchi K, Holtrich U, Holland S, Pawson T, Rubsamen-Waigmann H, Strebhardt K (1998) PDZdomain-mediated interaction of the Eph-related receptor tyrosine kinase EphB3 and the ras-binding protein AF6 depends on the kinase activity of the receptor. Proc Natl Acad Sci U S A 95:9779-9784.

Hornberger MR, Dutting D, Ciossek T, Yamada T, Handwerker C, Lang S, Weth F, Huf J, Wessel R, Logan C, Tanaka H, Drescher U (1999) Modulation of EphA receptor function by coexpressed ephrinA ligands on retinal ganglion cell axons. Neuron 22:731-742.

Kadison SR, Makinen T, Klein R, Henkemeyer M, Kaprielian Z (2006) EphB receptors and ephrin-B3 regulate axon guidance at the ventral midline of the embryonic mouse spinal cord. J Neurosci 26:8909-8914.

Kania A, Jessell TM (2003) Topographic motor projections in the limb imposed by LIM homeodomain protein regulation of Ephrin-A:EphA interactions. Neuron 38:581-596.

Kayser MS, McClelland AC, Hughes EG, Dalva MB (2006) Intracellular and trans-synaptic regulation of glutamatergic synaptogenesis by EphB receptors. J Neurosci 26:12152-12164.

Kullander K, Mather NK, Diella F, Dottori M, Boyd AW, Klein R (2001) Kinase-dependent and kinase-independent functions of EphA4 receptors in major axon tract formation in vivo. Neuron 29:73-84.

Lee R, Petros TJ, Mason CA (2008) Zic2 regulates retinal ganglion cell axon avoidance of ephrinB2 through inducing expression of the guidance receptor EphB1. J Neurosci 28:5910-5919.

Lemke G, Reber M (2005) Retinotectal mapping: new insights from molecular genetics. Annu Rev Cell Dev Biol 21:551-580.

Luria V, Krawchuk D, Jessell TM, Laufer E, Kania A (2008) Specification of motor axon trajectory by Ephrin-B:EphB signaling: symmetrical control of axonal patterning in the developing limb. Neuron 60:1039-1053.

Marcus RC, Blazeski R, Godement P, Mason CA (1995) Retinal axon divergence in the optic chiasm: uncrossed axons diverge from crossed axons within a midline glial specialization. J Neurosci 15:3716-3729.

Marquardt T, Shirasaki R, Ghosh S, Andrews SE, Carter N, Hunter T, Pfaff SL (2005) Coexpressed EphA receptors and ephrin-A ligands mediate opposing actions on growth cone navigation from distinct membrane domains. Cell 121:127-139.

Matsuda T, Cepko CL (2004) Electroporation and RNA interference in the rodent retina in vivo and in vitro. Proc Natl Acad Sci U S A 101:16-22.

McLaughlin T, O’Leary DD (2005) Molecular gradients and development of retinotopic maps. Annu Rev Neurosci 28:327-355.

Mendes SW, Henkemeyer M, Liebl DJ (2006) Multiple Eph receptors and $\mathrm{B}$-class ephrins regulate midline crossing of corpus callosum fibers in the developing mouse forebrain. J Neurosci 26:882-892. 
Nakagawa S, Brennan C, Johnson KG, Shewan D, Harris WA, Holt CE (2000) Ephrin-B regulates the Ipsilateral routing of retinal axons at the optic chiasm. Neuron 25:599-610.

Pak W, Hindges R, Lim YS, Pfaff SL, O’Leary DD (2004) Magnitude of binocular vision controlled by islet- 2 repression of a genetic program that specifies laterality of retinal axon pathfinding. Cell 119:567-578.

Pasquale EB (2005) Eph receptor signalling casts a wide net on cell behaviour. Nat Rev Mol Cell Biol 6:462-475.

Pasquale EB (2008) Eph-ephrin bidirectional signaling in physiology and disease. Cell 133:38-52.

Petros TJ, Williams SE, Mason CA (2006) Temporal regulation of EphA4 in astroglia during murine retinal and optic nerve development. Mol Cell Neurosci 32:49-66.

Petros TJ, Rebsam A, Mason CA (2008) Retinal axon growth at the optic chiasm: to cross or not to cross. Annu Rev Neurosci 31:295-315.

Stein E, Huynh-Do U, Lane AA, Cerretti DP, Daniel TO (1998a) Nck recruitment to Eph receptor, EphB1/ELK, couples ligand activation to c-Jun Kinase. J Biol Chem 273:1303-1308.

Stein E, Lane AA, Cerretti DP, Schoecklmann HO, Schroff AD, Van Etten RL, Daniel TO (1998b) Eph receptors discriminate specific ligand oligomers to determine alternative signaling complexes, attachment, and assembly responses. Genes Dev 12:667-678.

Torii M, Levitt P (2005) Dissociation of corticothalamic and thalamocortical axon targeting by an EphA7-mediated mechanism. Neuron 48:563-575.

Torres M, Gomez-Pardo E, Gruss P (1996) Pax2 contributes to inner ear patterning and optic nerve trajectory. Development 122:3381-3391.
Tsai NP, Bi J, Wei LN (2007) The adaptor Grb7 links netrin-1 signaling to regulation of mRNA translation. EMBO J 26:1522-1531.

Vanderhaeghen P, Lu Q, Prakash N, Frisen J, Walsh CA, Frostig RD, Flanagan JG (2000) A mapping label required for normal scale of body representation in the cortex. Nat Neurosci 3:358-365.

Vindis C, Cerretti DP, Daniel TO, Huynh-Do U (2003) EphB1 recruits c-Src and $\mathrm{p} 52^{\text {Shc }}$ to activate MAPK/ERK and promote chemotaxis. J Cell Biol 162:661-671.

Wang LC, Dani J, Godement P, Marcus RC, Mason CA (1995) Crossed and uncrossed retinal axons respond differently to cells of the optic chiasm midline in vitro. Neuron 15:1349-1364.

Williams SE, Mann F, Erskine L, Sakurai T, Wei S, Rossi DJ, Gale NW, Holt CE, Mason CA, Henkemeyer M (2003) Ephrin-B2 and EphB1 mediate retinal axon divergence at the optic chiasm. Neuron 39:919-935.

Williams SE, Grumet M, Colman DR, Henkemeyer M, Mason CA, Sakurai T (2006) A role for Nr-CAM in the patterning of binocular visual pathways. Neuron 50:535-547.

Wybenga-Groot LE, Baskin B, Ong SH, Tong J, Pawson T, Sicheri F (2001) Structural basis for autoinhibition of the Ephb2 receptor tyrosine kinase by the unphosphorylated juxtamembrane region. Cell 106:745-757.

Yun ME, Johnson RR, Antic A, Donoghue MJ (2003) EphA family gene expression in the developing mouse neocortex: regional patterns reveal intrinsic programs and extrinsic influence. J Comp Neurol 456:203-216.

Zisch AH, Pazzagli C, Freeman AL, Schneller M, Hadman M, Smith JW, Ruoslahti E, Pasquale EB (2000) Replacing two conserved tyrosines of the EphB2 receptor with glutamic acid prevents binding of $\mathrm{SH} 2$ domains without abrogating kinase activity and biological responses. Oncogene 19:177-187. 